\title{
SEASONAL VARIATION IN EGG HATCHING AND CERTAIN EGG PARAMETERS OF THE GOLDEN SILK SPIDER NEPHILA CLAVIPES (ARANEIDAE)*
}

\author{
By T. E. Christenson, P. A. Wenzl, and Peter Legum \\ Department of Psychology, Tulane University \\ New Orleans, LA 70118
}

\section{INTRODUCTION}

Little is known about seasonal variation in the reproductive success of spiders. Few field data, for example, are available on temperate egg productivity in relation to the phase of the season in which the female matured and in which the egg clutch was laid. Wise (1976) found that female filmy dome spiders (Neriene) who matured early in the summer laid more and lighter eggs than those who matured later. Levy (1970) noted that the early season crab spider (Thomisus) egg sacs contained more spiderlings than those laid toward the end of the season. Kessler (1973) noted that under field conditions the first egg sac of the wolf spider (Pardosa) contained more eggs than the second; it is probable that some of these late season clutches were the later ones produced by given females.

The present study focuses on the seasonal variation of egg hatching and certain egg parameters of a temperate population of the orb weaving Nephila clavipes. Mating occurs from July through September, with a given female mating several times just after her final molt (Christenson and Goist, 1979). Females may copulate after this period, but usually when feeding. Productive females lay their eggs in one to three elaborate egg sacs from mid-August through early December (Moore, 1977; Christenson and Wenzl, manuscript submitted). The female abandons the egg sac after its completion, directing no further attention toward it. Males die by late September and females by mid-December. Second instar spiderlings overwinter in the sac for six to eight months, and emerge under favorable conditions in the spring. The eggs have been described (Moore, 1977), and the functions of the egg sac and major causes of egg and early spiderling mortality have been discussed (Christenson and Wenzl, manuscript submitted).

*Manuscript received by the editor November 27, 1979 
In the present study we asessed seasonal variation in spiderling emergence through long term field observation of egg sacs laid throughout the restricted oviposition period. Seasonal variation in causes of failure to emerge, the number of eggs per clutch, individual egg weight, and the total egg clutch weight were also assessed.

\section{METHODS}

\section{Study Area}

The study area is located $20 \mathrm{~km}$ south of New Orleans, La. at the F. Edward Hebert Center of Tulane University. Observations were made within a bottomland hardwood forest cut by drainage ditches and dirt roads. Refer to Christenson and Wenzl (manuscript submitted) for a more detailed description of the study area. Observations were made during the 1975-1978 seasons.

\section{Procedures}

To determine if there was seasonal variation in spiderling emergence, we compared spring emergence data from egg sacs formed in early, mid, and late season. Each trimester was about six weeks in length. Throughout the egg laying season a set of pathways we had established in the cleared and forested areas were traversed systematically at least once a week in search of egg clutches. The only criterion for selection was that the egg sac be within $2.5 \mathrm{~m}$ of the ground. The approximate date the egg sac was formed was determined by the date of discovery, whether the eggs had hatched, and silk color, since the silk turned from white to gold within a week of being spun. Hatching was determined by gentle palpation of the egg sac. A total of 439 egg sacs were observed throughout the winters of 1975-1978; these accounted for about $60 \%$ of the total in the 3 ha study area. The decrease in foliage in winter exposed the egg sacs and facilitated a near total count. Each sac was tagged by placing tape on a nearby twig, and inspected periodically until spiderling emergence, beginning in March. We noted changes in egg sac structure and position, presence of fungus or predators, general condition of the eggs, hatching, and emergence from the sac. The 1975 and 1976 sacs were checked twice a week, the 1977 sacs once a week, and 1978 sacs weekly through January and monthly thereafter. Data from 1978, therefore, are not as complete as those from the previous years. 
To determine if there was a seasonal variation in individual egg weight, number of eggs per clutch, and total egg clutch weight, we collected and examined 63 egg sacs in 1977 and 93 in 1978. Egg clutches were removed from mid-August through early December. In 1977 weekly samples were taken from a thoroughly examined $1500 \mathrm{sq} \mathrm{mt}$ area within the hardwood forest. Only those egg sacs that appeared to contain yellow eggs were collected. In 1978 weekly samples were taken from a thoroughly examined $600 \mathrm{sq} \mathrm{mt}$ area of the hardwood forest bordering a cleared drainage ditch. Half of the egg sacs found in the latter area were randomly chosen for removal and examination, and half for observation throughout the winter in the field. The egg sacs brought into the laboratory were placed in Petri dishes, the inside covers of which were mist sprayed with water every other day. A normal day-night cycle and a temperature of about $22^{\circ} \mathrm{C}$ were maintained in the laboratory. About four days after collection the silk was removed from the sac, and the egg mass was weighed. The delay in handling was designed to minimize damage to the eggs, since they are particularly fragile for a few days after oviposition. The egg mass was carefully broken apart and the eggs counted. Within two days of counting a random sample of 10 yellow eggs was drawn from each clutch; each egg was weighed separately on a Mettler analytic balance.

\section{RESULTS}

Field observations revealed a seasonal variation in the emergence of spiderlings; they were less likely to emerge from egg sacs laid later in the season (Table 1). The numbers in Table 1 and under twig

Table 1. Percentage of egg sacs from which no spiderlings emerged in the spring according to the trimester of the season in which the egg sac was formed. Each trimester represents about six weeks. Estimated numbers of failures are in parentheses; see text for explanation of estimate. Trimester effect analyzed by Chi square test; data were collapsed across years. ${ }^{1}$

\begin{tabular}{lccr}
\hline Trimester: & \%-Early & $\%-$ Mid & \%-Late \\
\hline 1975 & $26.6(20.8$ of 78$)$ & $60.5(29.0$ of 48$)$ & $72.3(8.7$ of 12$)$ \\
1976 & $29.8(26.6$ of 89$)$ & $94.5(44.4$ of 47$)$ & $100.0(10.0$ of 10$)$ \\
1977 & $35.3(16.6$ of 47$)$ & $10.0(1.7$ of 17$)$ & $78.4(7.8$ of 10$)$ \\
1978 & $31.3(16.6$ of 53$)$ & $42.0(8.4$ of 20$)$ & $75.0(6.0$ of 8$)$ \\
\hline
\end{tabular}

$1 \mathrm{X}_{2}^{2}=62.45, \mathrm{p}<.001$ 
breakage in Table 2 are estimates based upon the fact that $84.2 \%$ (16 of 19) of the egg sacs that were found after falling to the ground failed to produce spiderlings. The three successful clutches fell within one month prior to the normal time of spring emergence. We estimated the number of failures by multiplying the number of egg sacs that fell by .84 . We feel this is a correct estimate since several clutches that were never found fell shortly before the normal time of emergence.

One major cause of mortality was egg inviability, distinguished by the hard and blackened nature of the eggs. There was a seasonal variation in inviability; it caused most of the late but few of the early season failures (Table 2). Its exact causes are not known, although fungus was not found on inviable eggs and no parasites emerged

Table 2. Causes of spiderling failure to emerge from the egg sac according to the trimester of the season in which the egg sac was formed. Actual numbers for the egg inviability and miscellaneous categories, and the estimates for twig breakage are in parentheses. ${ }^{1}$

Causes of Failure

\begin{tabular}{lccc}
\hline Year and Trimester: & \% Egg Inviability & \%Twig Breakage & $\%$ Misc. $^{3}$ \\
\hline 1975 Early & $19.3(4)$ & $56.6(11.8)$ & $24.1(5)$ \\
Mid & $55.1(16)$ & $17.4(5.0)$ & $27.5(8)$ \\
Late & $57.6(5)$ & $19.4(1.7)$ & $23.0(2)$ \\
$1976 \quad$ Early & $48.9(13)$ & $28.5(7.6)$ & $22.6(6)$ \\
Mid & $72.1(32)$ & $18.9(8.4)$ & $9.0(4)$ \\
Late & $80.0(8)$ & 0 & $20.0(2)$ \\
1977 Early & 0 & $75.9(12.6)$ & $24.1(4)$ \\
Mid & 0 & $100.0(1.7)$ & 0 \\
Late & $89.3(7)$ & $10.7(.8)$ & 0 \\
1978 Early & $24.1(4)$ & $75.9(12.6)$ & - \\
Mid & $59.8(5)$ & $3.4(4)$ & - \\
Late & $100.0(6)$ & 0 & 0 \\
\hline
\end{tabular}

'See text for explanation of estimate.

2Includes the cases in which the twig fell after the eggs hatched.

${ }^{3}$ Misc. includes immobility (3), loss of leaf canopy (3), damage to the silk surrounding the eggs (2), fungus (10), and predation (7). The 1978 egg sacs were not observed as often as those in previous years; therefore, causes under this category can not be assessed with the accuracy possible for the previous years. 
from samples brought into the laboratory. There was also seasonal variation in the second major cause of mortality, twig breakage; early season sacs fell more frequently than those formed later (Table 2). Twig breakage resulted in the eggs falling to the ground, and subsequently rotting or being preyed upon. No seasonal variation, however, was noted in the frequency of failures caused by immobility of the egg sac after lodging on a branch, loss of the leaf canopy over the eggs, damage to the silk covering the eggs, fungus, or predation (Table 2).

Seasonal variation in certain egg parameters were also noted. Individual egg weight in clutches laid early in the season was significantly greater than in those laid later (Table 3 ). The same was true for total egg weight. The early 1978 clutches also contained significantly more eggs (Table 3 ), but no significant relationship was found between individual egg weight and number within a clutch. The Pearson correlations between these two parameters in 1977 and 1978 were $\mathrm{r}=+.068 \mathrm{~F}_{1.42}=.20, \mathrm{p}>.05$ and $\mathrm{r}=+.202\left(\mathrm{~F}_{1.82}=3.44\right.$, $\mathrm{p}>.05)$, respectively.

\section{DISCUSSION}

Seasonal variation in spiderling emergence may be due, in part, to climatic factors. Clutches laid early in the season are exposed for a longer period of time to wind and rain which, in turn, may increase the likelihood of those clutches falling to the ground. Moreover, the early part of the egg laying season coincides with the peak of the hurricane and rainy season which may cause a higher frequency of twig breakage, the major cause of failure among early season clutches.

Climatic factors may also contribute to the increase in egg inviability of clutches laid later in the season. For example, the cooler temperatures later in the season may significantly delay hatching, similar to that found in temperate N. edulis (Austin and Anderson, 1978). Christenson and Wenzl (manuscript submitted) have shown that $N$. clavipes eggs are particularly vulnerable to some causes of mortality during the three week period prior to hatching. Cooler temperatures may also reduce the amount of prey available to adult females, thereby hampering egg production.

The seasonal variation in inviability could also be due, in part, to the maturation of the adult. Some of the late season clutches are probably the later ones produced by given females. Horner and 


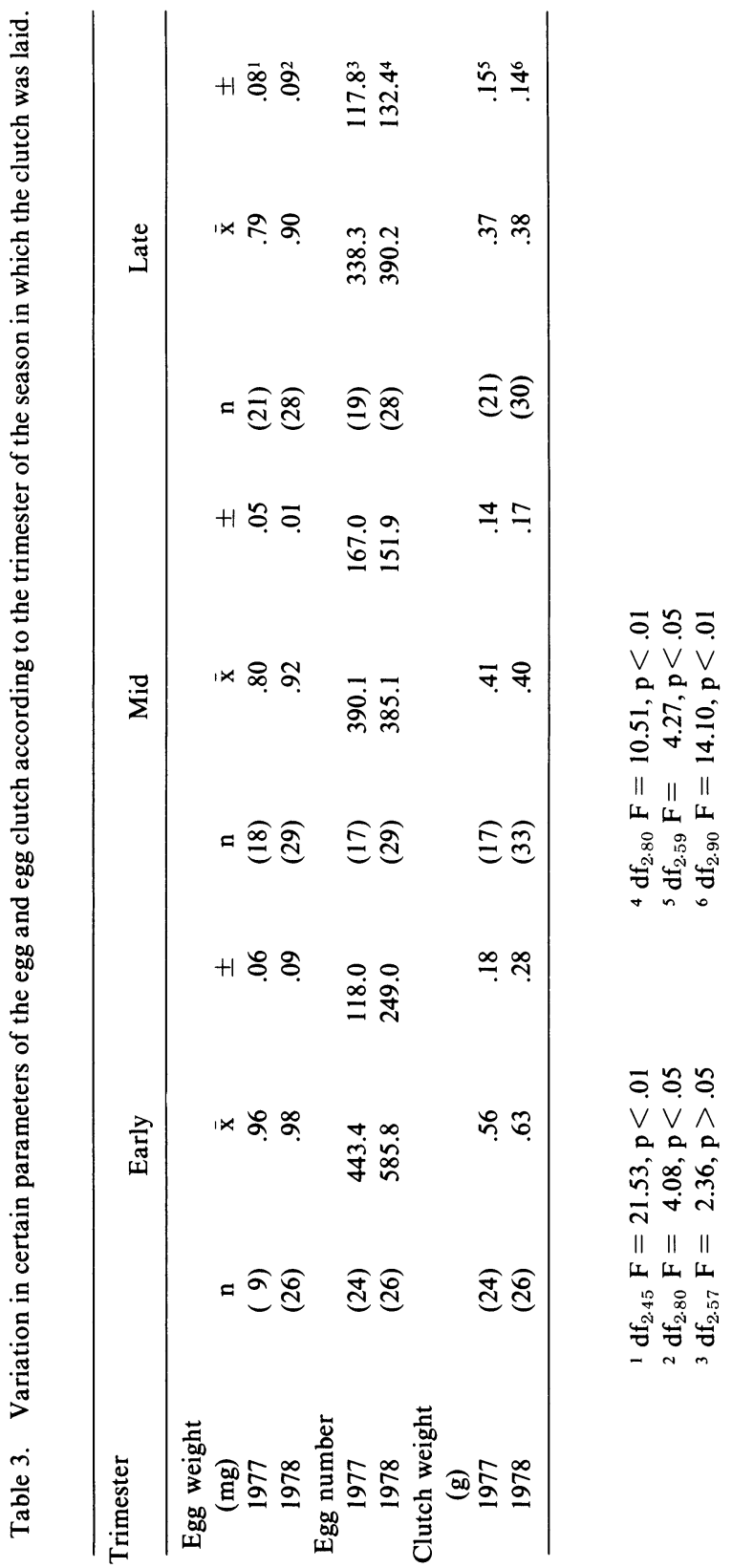


Starks (1972) and Jackson (1978) found that eggs of the second clutch of Metaphidippus and Phidippus, respectively, hatch with a lower frequency than those from the first clutch. Gametic inviability, infertility due to sperm depletion, and the production of "trophic" eggs as food for the first few instars could, in part, explain the lower frequency of late season hatching (Jackson, 1978). The timing of maturation may also relate to inviability. From their study of temperate $N$. maculata, Thakur and Tembe (1956) suggest that some females may mature late in the season after the disappearance of males. Eggs laid by these females, therefore, could be infertile and inviable. This assumes that parthenogenesis does not occur in $N$. clavipes; an assumption that has yet to be evaluated. The timing of male maturation may also be significant; males maturing on their own orbs toward the end of the season may be less healthy and vigorous due to reduced prey availability. Some males who mate at the end of the season may be older and incapable of normal spermatogenesis. We are presently assessing the relationship of egg inviability to sperm depletion, seasonal variation in male vigor, and the extent to which females mature after the males have disappeared. We are also attempting to determine if parthenogenesis occurs in our population.

Wise (1976) has noted that Linyphia egg weight may be adapted to the temperate ecology of his population. He suggested that eggs laid later in the season were heavier as an adaptation to the reduced amount of prey available to spiderlings who mature late in the summer. Similarly, the seasonal variability of $N$. clavipes egg weights may be an adaptation to the length of the overwintering period. Since eggs laid early in the season must overwinter one to two months longer than those laid afterwards, spiderlings from early clutches may require additional yolk to maintain themselves during this period. If we assume a relationship between egg weight and spiderlng weight at emergence, then large early season egg size may minimize the chances that early spiderlings would be at a competitive disadvantage upon emergence in the spring (Kessler, 1971). To understand the role of egg weight as an adaptation to a temperate ecology, we must examine its relationship not only to egg number, discussed below, but also to the possibility that siblings may prey and/or feed upon one another during the overwintering period. We are currently examining the relationships between these variables and spiderling survival. 
The decreased weight of individual eggs laid near the end of the season may be due to reduced female prey intake as a function of prey availability at this time. Turnbull (1962) and Kesler (1971) have noted that prey intake can, in part, determine egg weight in Linyphia and Pardosa, respectively. This could explain why the egg sacs we collected in 1978 appeared to contain heavier eggs than those collected in 1977. In 1978 eggs came from an area of the forest bordering a cleared drainage ditch near which many adult females maintained orbs. During the mating season the biomass of flowering plants and prey seemed much greater and the females relatively larger in this area. In contrast, 1977 clutches were collected from within the forest, where the biomass of prey and female size seemed restricted. We obviously need to do more sampling. Habitat can, however, influence egg productivity. Kessler (1973) noted that the variance in the number of eggs produced by Pardosa in different localities was greater than that noted in the same locality from year to year.

Reduced prey intake by the female near the end of the season may also reduce the number of eggs in later clutches. Kessler (1971) noted that in some species of Pardosa decreased food intake resulted in fewer eggs per clutch. This decrease in egg number could also be explained, in part, by the observation that successive clutches contain fewer eggs in $N$. maculata (Bonnet, 1930) and in a variety of other genera (Phidippus-Jackson, 1978, and Gardner, 1965; Tegenaria-Mikulska and Jacunsksi, 1968; AchaearaneaValerio, 1976; Enoplognatha-Seligy, 1971; and ChiracanthiumPeck and Whitcomb, 1970). In Linyphia female size is related to egg number in that clutches of the larger early maturing females contained more eggs than those of smaller later maturing females (Wise, 1976).

In an interesting discussion Jackson (1978) suggested that female Phidippus may invest more of their energy in the first clutch as an adaptation to the increased risk of desiccation and reduced prey availability experienced by spiderlings from later clutches. Early season $N$. clavipes might invest more of their reproductive energy, in terms of egg number, in the first clutch as an adaptation to the possible detrimental effects of cooler late season temperatures. We suspect that the number of spiderlings in a clutch determines, in large part, how successful the siblings are at constructing a succes- 
sion of normal communal webs, and maintaining group integrity during the communal phase prior to dispersal. We are currently examining the relationship of egg and spiderling numbers to the behavior and success of spiderlings after emergence from the egg sac.

It has been suggested that individual egg weight might be reduced to produce more eggs, or vice versa (Kessler, 1973; Jackson, 1978). Individual female $N$. clavipes do not adopt such a strategy. Examination of several clutches produced by our population indicate that these two parameters do not vary systematicaly with one another. The relationship between egg number and egg weight may be useful, however, when applied to differences between well defined populations or closely related species.

Nephila is primarily a tropical genus that has expanded into temperate climates, which we suspect results in seasonal variation in egg productivity and probably individual reproductive success. In the tropics less seasonal variation would be expected, since climate and prey availability are more stable, and since adults may mature, mate, and oviposit throughout the year. Individual tropical Nephila eggs may be relatively light, since after hatching the spiderlings probably remain in the egg sac for a shorter period, and require less yolk. If this were the case, tropical clutches might also contain more eggs than temperate clutches. We calculate from data presented by Robinson and Robinson (1976) that topical $N$. maculata eggs weigh about $.49 \mathrm{mg}$, while we have shown that temperate $N$. clavipes eggs weigh about $.89 \mathrm{mg}$. It also appears that tropical $N$. maculata clutches contain about six to eight times the number of eggs as those of temperate $N$. edulis (Austin and Anderson, 1978) and $N$. clavipes. The comparative study of $N$. clavipes under temperate and tropical conditions would contribute to our understanding of reproductive strategies as adaptations to ecological conditions.

\section{ACKNOWLEDGEMENTS}

The authors wish to thank Allison Shack, Robert Moore, Mike Sheltzer, and George Ehringer for their help in the field, and Kenneth Goist for his comments on the manuscript. 


\section{REFERENCES}

Austin, A. D. And D. T. Anderson

1978. Reproduction and development of the spider Nephila edulis (Koch) (Araneidae:Araneae). Aust. J. Zool. 26: 501-518.

BONNET, P.

1930. Les araignees exotiques en Europe II. Elevage a toulouse de la grande Araignee fileuse de Madagascar et considerations sur l'Araneiculture. Bull. Soc. Zool. France 55: 53-77.

Christenson, T. E. and K. C. Goist, JR.

1979. Costs and benefits of male-male competition in the orb weaving spider, Nephila clavipes. Behav. Ecol. Sociobiol. 5: 87-92.

Christenson, T. E. AND P. A. Wenzl

1979. Egg laying of the golden silk spider, Nephila clavipes L. (Araneae, Araneidae): Functional analysis of the egg sac. Manuscript submitted.

GARDNER, B. T.

1965. Observations on three species of Phidippus jumping spiders (Araneae: Salticidae). Psyche 72: 133-147.

Horner, N. V. AND K. J. STARKS

1972. Bionomics of the jumping spider Metaphidippus galathea. Ann. Entomol. Soc. America 65: 602-607.

JACKSON, R. R.

1978. Life history of Phidippus johnsoni (Araneae, Salticidae) J. Arachnol. 6: $1-29$.

Kessler, A.

1971. Relation between egg production and food consumption in species of the genus Pardosa (Lycosidae, Araneae) under experimental conditions of food-abundance and food-shortage. Oecologia 8: 93-109.

Kessler, A.

1973. A comparative study of the production of eggs in eight Pardosa species in the field (Araneae, Lycosidae). Tijdschrift voor Entomologie 116: 23-41.

LEVY, G.

1970. The life cycle of Thomisus onustus (Thomisidae:Araneae) and outlines for the classification of the life histories of spiders. J. Zool. Lond. 160: 523-536.

MiKulSKa, 1. AND L. JACUNSKI

1968. Fecundity and reproduction activity of the spider Tegeneria atrica C. L. Koch. Zool. Pol. 18: 97-106.

MOORE, C. W.

1977. The life cycle, habitat and variation in selected web parameters in the spider, Nephila clavipes Koch (Aranediae). Amer. Midl. Nat. 98: 95-108.

Peck, W. B. AND W. H. Whitcomb

1970. Studies on the biology of a spider Chiracanthium inclusum (Hentz). Agr. Expd. Sta., Div. Agr., Univ. Arkansas Bull. No. 753.

RoBinson, M. H. AND B. RoBINSON

1976. The ecology and behavior of Nephila maculata: A supplement. Smithson. Contrib. Zool. 218: 1-22. 
Seligy, V. L.

1971. Postembryonic development of the spider Enoplognatha ovata (Clerck) (Araneae: Theridiidae). Zool. J. Linn. Soc. 50: 21-31.

Thakur, M. K. AND V. B. Tembe

1956. Bionomics of the giant wood spider, Nephila maculata Fabr. J. Bomb. Nat. Hist. Soc. 53: 328-334.

Turnbull, A. L.

1962. Quantitative studies of the food of Linyphia triangularis Clerck (Araneae:Linyphiidae). Can. Entomol. 94: 1233-1249.

VALERIO, C. E.

1976. Egg production and frequency of oviposition in Achaearanea tepidariorum (Araneae, Theridiidae). Bull. Br. Arach. Soc. 3: 194-198.

WISE, D. H.

1976. Variable rates of maturation of the spider, Nerience radiata (Linyphia marginata). Amer. Mid. Nat. 96: 66-75. 

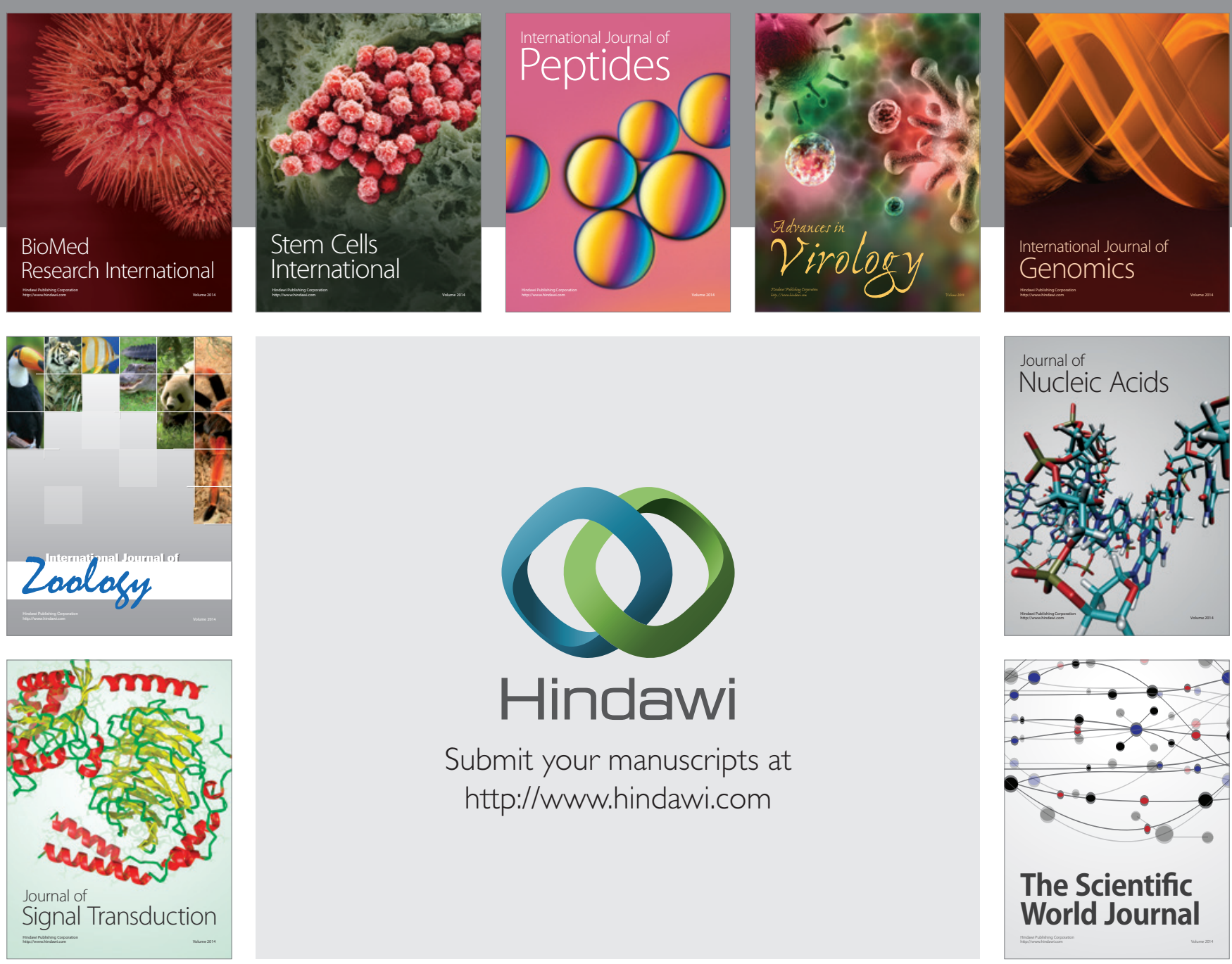

Submit your manuscripts at

http://www.hindawi.com
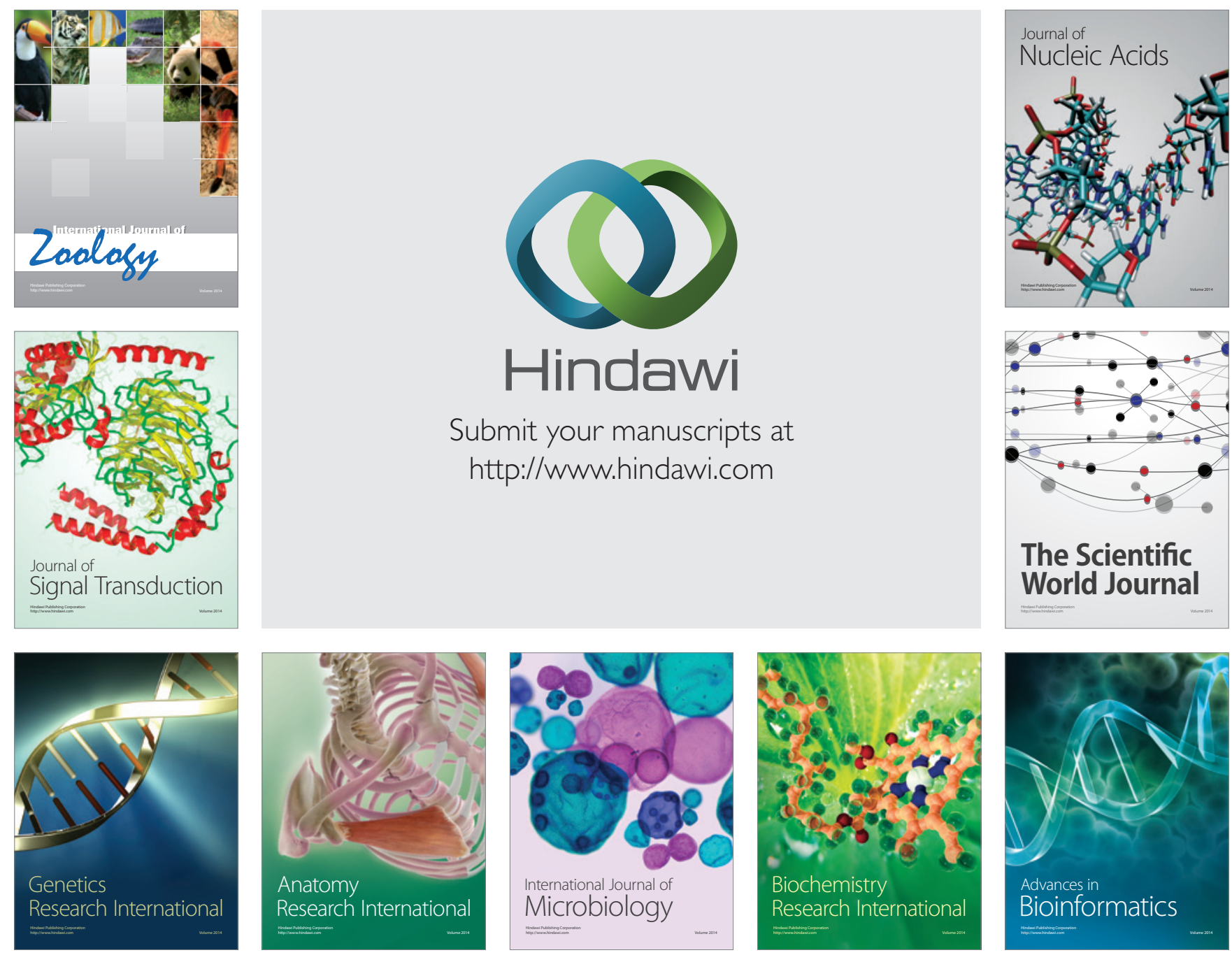

The Scientific World Journal
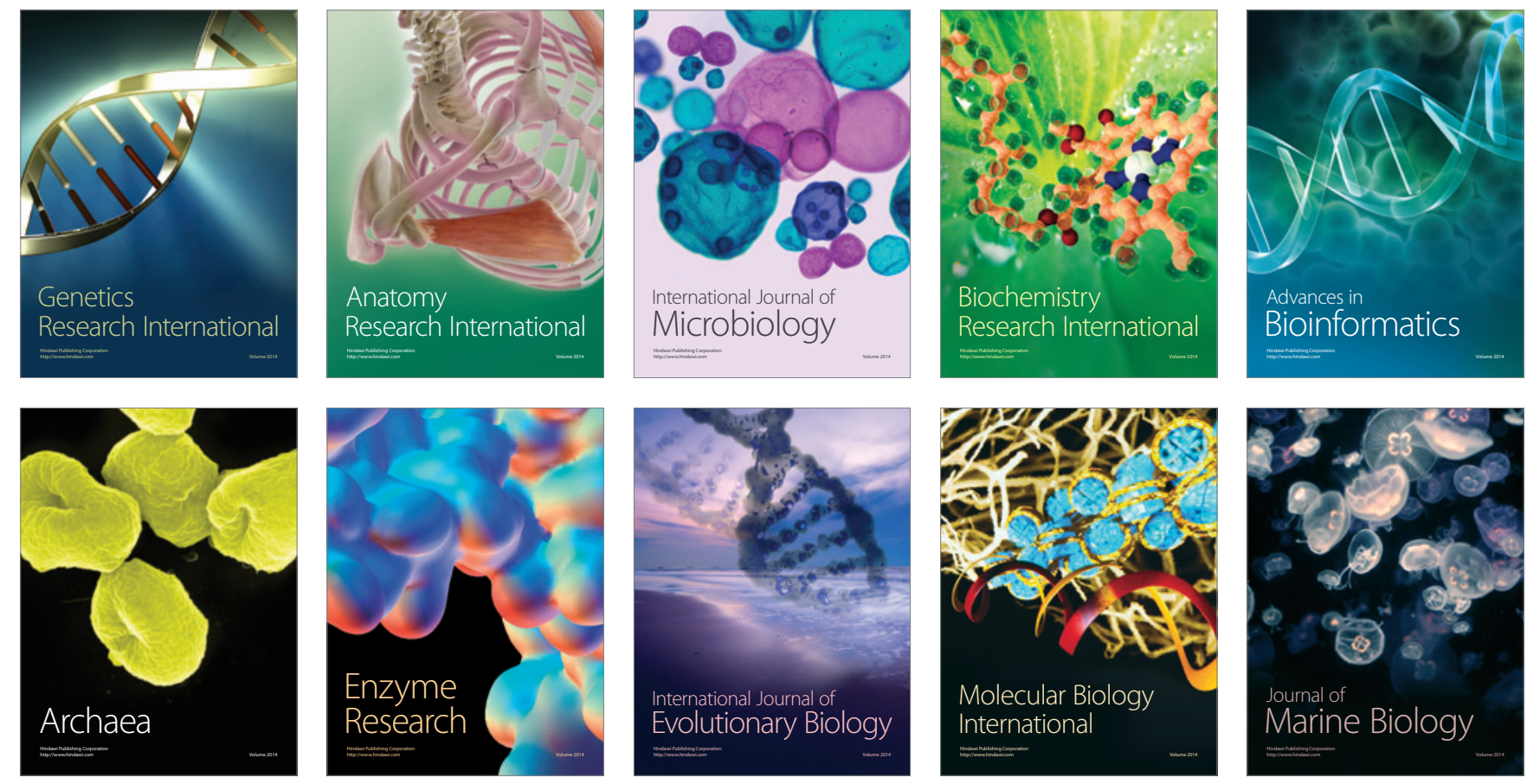